\title{
Author Correction: Liraglutide Improves Cardiovascular Risk as an Add-on to Metformin and Not to Insulin Secretagogues in Type 2 Diabetic Patients: A Real-life 48-Month Retrospective Study
}

Alessandro Ciresi · Enrica Vigneri · Stefano Radellini · Felicia Pantò ·

Carla Giordano (1)

Published online: April 10, 2018

(c) The Author(s) 2018

Author Correction to: Diabetes Ther (2018)

$$
\begin{aligned}
& \text { 9:363-371 } \\
& \text { https://doi.org/10.1007/ } \\
& \text { s13300-017-0338-4 }
\end{aligned}
$$

In the original publication, the funding statement was incorrectly published and the Editorial Assistant information was missed in the published version. The correct funding statement and the Editorial Assistant statement should read as below.

Funding. The study and article processing charges were funded by Novo Nordisk S.p.A. All authors had full access to all of the data in this study and take complete responsibility for the integrity of the data and the accuracy of the data analysis.
Editorial Assistance. Editorial assistance was provided by Paolo de Gennaro of Airon Communication. Support for this assistance was funded by Novo Nordisk S.p.A.

Open Access. This article is distributed under the terms of the Creative Commons Attribution-NonCommercial 4.0 International License (http://creativecommons.org/licenses/ by-nc/4.0/), which permits any noncommercial use, distribution, and reproduction in any medium, provided you give appropriate credit to the original author(s) and the source, provide a link to the Creative Commons license, and indicate if changes were made.

The original article can be found online at https://doi. org/10.1007/s13300-017-0338-4.

A. Ciresi · E. Vigneri - S. Radellini - F. Pantò .

C. Giordano $(\square)$

Section of Endocrinology, Biomedical Department of Internal and Specialist Medicine, University of Palermo, Palermo, Italy

e-mail: carla.giordano@unipa.it 